Proposta OUC Nova BH
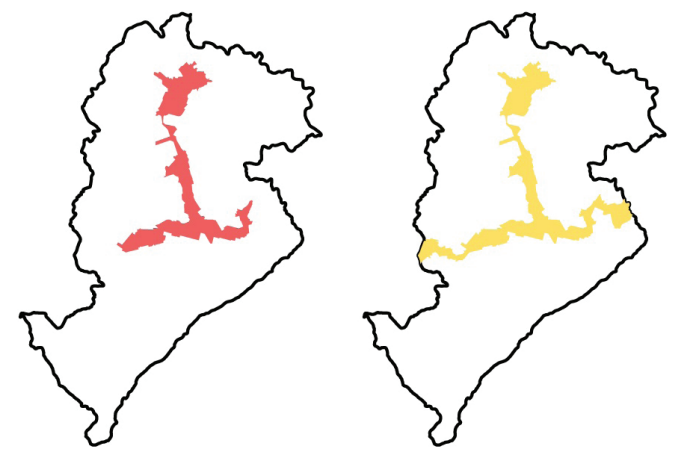

\title{
Técnico versus participativo: discursos de uma disputa ${ }^{1}$
}

Technical versus participatory: discourses of a dispute

Thaís Mariano Nassif Salomão*

\section{Resumo}

A partir de um referencial teórico, que salienta o caráter político da disputa pela cidade, este artigo busca um melhor entendimento a respeito das materialidades simbólicas que integram essa disputa. Uma recuperação histórica da ascensão da participação em meio ao tradicionalmente tecnocrático campo do planejamento urbano brasileiro delimi-

${ }^{*}$ Graduada e mestre em Arquitetura e Urbanismo pela Universidade Federal de Minas Gerais (UFMG). Vencedora do X Prêmio Brasileiro "Politica e Planejamento Urbano e Regional\&quot; de Dissertações de Mestrado (ANPUR). Professora da Pontifícia Universidade Católica de Minas Gerais (PUC-MG), bolsista de extensão do Observatório das Metrópoles Instituto Nacional de Ciência e Tecnologia (INCT) - e pesquisadora do grupo de pesquisa Praxis-UFMG. ta o técnico e o participativo como discursos de poder que se contrapõem na tomada de decisão sobre o espaço urbano. Estabelecido o contexto histórico desta reflexão, o processo participativo tardio vinculado à proposta de implantação de uma Operação Urbana Consorciada no município de Belo Horizonte serve de objeto para o apontamento da relevância de tal disputa. Trata-se de uma disputa não apenas entre esses dois discursos, mas também pelo significado desses termos - técnico e participativo - como via essencial para uma produção mais democrática do espaço.

Palavras-chave: Planejamento urbano. Participação social. Linguagem técnica

\section{Abstract ${ }^{5}$}

Based on a theoretical framework that emphasizes the political character of the dispute on the city, this article proposes a better understanding of the symbolic materialities that take part on this dispute. A historical perspective on the rise of participation within the traditionally technocratic field of urban planning in Brazil sets out the technical and the participatory as conflicting discourses within decision making processes related to urban space production. Meanwhile the institutionalized participatory process related to the proposal of an Urban Operation Consortium in the city of Belo Horizonte serves as a backdrop for pointing out the relevance of such dispute. It is a dispute not only between these two discourses, but also on the meaning of these concepts - technical and participatory - as an essential pathway for a more democratic production of space.

Keywords: Urban planning. Social participation. Technical language. cas/ST\%2010/ST\%2010.5/ ST\%2010.5-03.pdf. 


\section{Introdução}

A transformação do território urbano é também uma disputa por cidadania que se dá no campo político do discurso. Este artigo se propõe a explorar algumas das implicações de articulações de poder simbólico a partir dos discursos técnico e participativo utilizadas para a fundamentação e justificativa de processos de tomada de decisão junto ao campo do planejamento urbano. Através dessa exploração propõe-se aprofundar 0 conhecimento a respeito dos termos em que se dá a disputa pela cidade no contexto brasileiro e explicitar possibilidades de exploração desses discursos como estratégias de perturbação da ordem socioespacial imposta.

Para o desenvolvimento das questões enunciadas, adota-se um referencial teórico marxista que salienta o caráter político da disputa pela cidade, assim como dos discursos a serem analisados. Na primeira parte deste artigo, a partir de Michel de Certeau, explora-se o entendimento de es- tratégias de produção e táticas de consumo de materialidades simbólicas como formas de manipulação sobre o querer do outro. Em seguida, na segunda parte deste artigo, uma recuperação histórica da ascensão da participação em meio ao tradicionalmente tecnocrático campo do planejamento urbano brasileiro delimita o técnico e o participativo como discursos de poder que se contrapõe na tomada de decisão sobre o espaço. Compõe-se assim o plano de fundo para a observação desse embate junto a um objeto empírico: o processo participativo vinculado à elaboração do plano urbanístico da Operação Urbana Consorciada (OUC) Antônio Carlos/Pedro I + Leste-Oeste (ACLO), realizado entre outubro de 2014 e maio de 2015 no município de Belo Horizonte.

$\mathrm{Na}$ terceira parte deste artigo, destaca-se a relevância desse embate discursivo na defesa e na critica das Operações Urbanas Consorciadas como controversos instrumentos de planejamen- 
to urbano. Em seguida, esse embate é evidenciado também a partir do conturbado histórico que antecede o processo participativo da OUC ACLO. Finalmente, são problematizadas apropriações discursivas que se destacaram a partir do acompanhamento dos fóruns participativos e de entrevistas realizadas com participantes e organizadores neles envolvidos a partir das materialidades simbólicas por eles acionados. Em conclusão, aponta-se para a disputa não apenas entre os discursos técnico e participativo, mas também pelo significado desses termos como via essencial para uma produção mais democrática do espaço.

\section{Fundamentação teórica: discursos em disputa}

\section{Uma disputa por cidadania}

A cidade é o cenário privilegiado da reprodução social, lócus do excedente, do poder e da festa. Tanto em sua forma espacial quanto em sua organização social, ela condiciona as várias formas de distribuição populacional e constituição comunitária e atua como referência de identidades sociais desempenhando um papel fundamental na estruturação da vida contemporânea (MONTE-MÓR, 2006). Assim, ainda que um dos projetos fundamentais de construção da nação moderna tenha sido o desmantelamento da primazia clássica da cidadania urbana e a sua substituição pela cidadania nacional, as cidades contemporâneas permanecem sendo arenas estratégicas para a construção discursiva e contextual de relações chamadas de cidadania (HOLSTON, 2013).
Ou seja, não apenas concentram um conjunto de atributos específicos capazes de conjurar o pertencimento dos sujeitos a uma sociedade, mas também de irromper o desenvolvimento de imaginários políticos.

Entretanto, em uma perspectiva marxista, as cidades contemporâneas, como produtos do trabalho humano e alicerces das sociedades capitalistas industriais modernas são, sobretudo, objetos de disputa. As formas assumidas pelo tecido urbano encontram-se estritamente ligados ao solo, à terra - uma mercadoria não reproduzível - e são resultado da disputa em relação aos valores de troca e de uso dessa mercadoria escassa. Como descreve Lefebvre (2001), trata-se de uma disputa desigual em que a primazia dos valores de troca sobre os valores de uso da terra urbana tem como consequência direta e sintoma latente a segregação que assola a cidade contemporânea, deforma-a morfologicamente e ameaça a vida urbana.

Segundo Holston (2013), o empoderamento necessário para a luta por uma vida cotidiana merecedora da dignidade de cidadão acontece quando este reconhece uma fonte objetiva de direito. $O$ autor justifica que esse reconhecimento implica em uma noção correspondente de poder subjetivo, de mudar arranjos existentes (legais e outros) e de exigir o cumprimento desse direito. $\mathrm{O}$ conceito de direito à cidade, cunhado a partir do reconhecimento da relevância dos valores de uso da terra urbana, clama justamente pela liberdade 
de transformação da cidade: mais do que o acesso àquilo que já existe, um fazer e refazer nós mesmos e nossas cidades coletivamente (LEFEBVRE, 2001). Justamente o reconhecimento desse direito necessário para o empoderamento do cidadão, segundo influentes autores, permaneceria incompleto na sociedade contemporânea.

Nas palavras de Lefebvre (2001, p. 10): "as questões relativas à Cidade e à realidade urbana não são plenamente conhecidas e reconhecidas; ainda não assumiram politicamente a importância e o significado que têm no pensamento (na ideologia) e na prática". Para tratar de fenômeno semelhante, aproximando-se à realidade brasileira atual, Maricato (2002) cunha o termo "analfabetismo urbanístico". Segundo a autora, grande parte da população brasileira - em que se incluem também muitos especialistas: urbanistas, geógrafos, economistas etc. - desconhece as forças que moldam as cidades. Assim, o combate/erradicação deste "analfabetismo" seria necessário e urgente para que as questões relativas à cidade e à realidade urbana assumissem politicamente a importância e o significado que têm na luta por cidadania e dignidade.

\section{O discurso como combate político pela ver-} dade

O caráter político da incompletude do reconhecimento do direito à cidade como componente central da luta por cidadania na sociedade con- temporânea aponta para a necessidade de definição do conceito de político. Neste artigo propõe-se a adoção de um entendimento do termo desvinculado de sua atribuição como o conjunto de arranjos e instituições a partir dos quais se consolidou a ideia moderna de Estado e a aproximação à sua definição dada por Pogrebinschi (2009). A partir das teorias de Spinoza e Marx, a autora propõe um entendimento do político como unidade da constituição do ser individual e social e, assim, como parte constitutiva da experiência humana, ao passo que a experiência humana é também entendida como uma parte constitutiva do político. Ou seja, segundo a autora, juntos, experiência humana e experiência política, constituem-se como um todo que só pode ser compreendido pela indissociabilidade de suas partes. Assim, ao longo deste artigo, ao tratar do político propõe-se um entendimento do termo como experiência e prática cotidiana de vida socialmente compartilhada.

Em complementaridade a este entendimento do político, para a utilização do termo ideologia propõe-se aqui adotar seu entendimento tal como expresso em Bourdieu (1989) como uma associação de representações e ideias - ferramentas simbólicas - que determinado indivíduo ou grupo social produz a respeito de seu meio e de sua função nesse meio voltadas à imposição ou à legitimação de relações de dominação. Representações e ideias que devem sua estrutura às condições sociais de sua produção e circulação 
e que, sendo capazes de apresentar interesses particulares como se fossem universais, influem sobre a função política do sistema simbólico que compõe a constante disputa por lugares de poder.

Assim, entendendo o discurso como os complexos processos pelos quais nos comunicamos uns com os outros sobre um determinado tópico, que, refletidos em textos, conversas e aplicações práticas, transformam-se ao longo do tempo, tem-se a concepção de que todo discurso é ideológico. Seu caráter ideológico se estabelece na medida em que toma parte de um combate "pelo universal" ou "pela verdade" ou, ao menos, "em torno da verdade", em torno do estatuto da verdade e do papel político que ela desempenha.

\section{Materialidades simbólicas: estratégias de pro- dução e táticas de consumo.}

Para Michel de Certeau, a linguagem, ou, mais especificamente, a retórica ou ciência das "maneiras de falar", oferece um aparelho de figuras para a análise das maneiras cotidianas de fazer. Segundo o autor, o ato da palavra, coisa mais facilmente captada, registrada, transportada e abordada do que a prática em si, não pode ser separado da circunstância em que ela é pronunciada. Assim, a descrição dos "rodeios" de uma língua pode ser simultaneamente o lugar e o objeto de manipulações relativas às ocasiões e às maneiras de mudar (seduzir, persuadir, utilizar) o querer do outro. No espaço da linguagem (como no dos jogos), uma sociedade explicitaria as regras formais do agir e de seus fundamentos e, nesse espaço, duas lógicas da ação - a produção e o consumo - se depreenderiam de duas maneiras de praticar a linguagem - a estratégica e a tática.

Segundo o autor, essas duas formas linguajeiras se diferenciam de modo que, enquanto as estratégias são capazes de "produzir, mapear e impor" materialidades simbólicas expressas em um discurso, as táticas só podem "utilizá-las, manipulá-las e alterá-las", provocando inversões discretas a partir de seu consumo. As estratégias se caracterizariam pelo cálculo (ou a manipulação) das relações de forças que se torna possível quando um sujeito de querer e poder gerencia as relações com uma exterioridade de alvos ou ameaças. Enquanto as táticas seriam metáforas da ordem dominante que a fazem funcionar em "outro registro", inversões fundamentais na concepção política do agir quase invisíveis, por não se fazerem notar com produtos próprios, mas nas maneiras de empregar os produtos impostos por uma ordem dominante.

Nesse sentido, para o exame e caracterização de apropriações das materialidades simbólicas dos discursos técnico e participativo tal como expressas nos textos aqui analisados, propõe-se, ainda a partir de Certeau, a introdução da ideia de contra estratégias de ação social. Ou 
seja, formulações que se diferenciam das táticas por sua temporalidade distanciada da espontaneidade da prática e por seu caráter de tentativa de produção (de mapeamento e imposição calculados). Mas que, simultaneamente, são ainda caracterizadas pelo consumo (pela manipulação, alteração e inversão) dos produtos impostos por uma ordem dominante superior de forma a situa-los em outro registro.

\section{Uma perspectiva histórica: tradição tecnocrá-} tica e ascensão da participação

A Revolução Industrial e o estabelecimento do capitalismo como sistema econômico dominante provocaram dramáticas transformações na configuração das cidades, particularmente na Europa Ocidental. A radicalidade dessas transformações em meio ao surgimento da modernidade deram espaço à análise científica e objetificada do espaço urbano a partir das demandas de trafego e higiene. Os discursos de racionalidade, eficiência e moralidade se estabelecem como resposta à superpopulação e à desordem, ou à metafórica "cidade doente" (ESCOBAR, 2010). No campo do planejamento urbano como em tantos outros, a crença moderna em uma ciência neutra e autônoma reivindica a adequação da técnica para a tomada de decisão pública. Assim, a técnica e seus saberes, velados por uma linguagem especialista codificada, assume papel de destaque não apenas na prática, mas no discurso que define o campo do planejamento urbano.
As primeiras críticas a esse modelo tecnocrata, heterônomo e centralizador de planejamento surgem ainda em fins dos anos 1950 dando início ao embate discursivo abordado neste trabalho. Mas é apenas a partir dos anos 1970 que os jargões "participação" e "participativo" ganham força internacionalmente, quando o fracasso de planos de ajuda a países "subdesenvolvidos" e "em desenvolvimento" passa a ser atribuído à exclusão das populações afetadas do processo de concepção e implementação de projetos (RAHNEMA, 2010). Ativistas sociais e, gradualmente, parte dos próprios especialistas passam a defender o fim das estratégias de ação top-down (de cima para baixo) e a reivindicar a inclusão de métodos participativos como dimensão essencial para o desenvolvimento urbano.

No Brasil, concepções urbanísticas reformadoras e práticas de racionalidade administrativa europeias são sistematicamente importadas no decorrer do século XX e consolidam o planejamento urbano como uma ideologia de Estado (AZEVE$D O, 2011)$. Cabe ainda destacar que tal processo se deu particularmente durante o período militar, estabelecendo uma tradição para o campo que perpassa correntes como o higienismo-funcional e o tecno-burocratismo, de forte caráter modernizador, nacionalista e desenvolvimentista (RIBEIRO; CARDOSO, 1990).

Por sua vez, a participação social passa a ser defendida no contexto nacional marcadamente 
a partir da década de 1980, quando há um reflorescimento dos ideais de uma Plataforma de Reforma Urbana refreada durante o período mili$\operatorname{tar}$ (MARICATO; SANTOS JUNIOR, 2011). Nesse período, prefeituras autodenominadas democrático-populares - entre as quais se destaca a do município de Belo Horizonte, objeto deste trabaIho - passam a buscar a eficiência por meio do estabelecimento de novos canais de compartiIhamento do poder com a população. Em meio a políticas e reformas implementadas para atender aos princípios da legislação constitucional de 1988 , surgem na escala municipal novas práticas como a instituição de Conselhos de Política Urbana e de programas de Orçamento Participativo $(\mathrm{OP})$.

Hoje, a participação social junto ao campo do planejamento urbano é uma conquista legal na escala nacional, obrigatória para a formulação, execução e acompanhamento de planos, programas e projetos de desenvolvimento urbano (BRASIL, 2001). No entanto, como afirma Montenegro (2011), em reação ao processo de redemocratização aqui descrito, tem início uma construção contínua de procedimentos técnicos que visavam garantir maior racionalidade nas escolhas da população e a reinserção dos processos participativos na lógica tecnocrata corrente do planejamento urbano. Em Belo Horizonte, por exemplo, à medida que o OP se tornava rotina, foram se estabelecendo regras definidas pelo Executivo e critérios técnicos em consonância com diretrizes que direcionavam as escolhas da população (MONTENEGRO, 2011).

A complexidade técnica e social de grande parte dos programas e políticas urbanas contemporâneas, um grau significativo de competência é requerido do cidadão, assim como de seus representantes eleitos, para que uma participação efetiva na tomada de decisões seja possível. Se os cidadãos ou aqueles que os representam são incapazes de compreender e fazer julgamentos inteligentes a respeito dos complexos temas da cidade contemporânea, tem-se um problema em relação à aplicabilidade da democracia. No entanto, a reivindicação tradicional de uma ciência neutra e autônoma e, portanto, perfeitamente adequada à tomada de decisão pública tampouco se sustenta, em virtude do evidente processo de mercantilização do conhecimento científico, repetidamente colocado a serviço de interesses econômicos e políticos. Estabelecem-se, assim, os termos da disputa.

\section{A Operação Urbana Consorciada Antônio Car- los/Pedro I + Leste-Oeste}

\section{Sobre o instrumento: complexidade técnica e redenção pela participação}

A complexidade técnica e operacional das Operações Urbanas Consorciadas, sofisticada modalidade de parceria público-privada estabelecida como instrumento de planejamento urbano pelo Estatuto da Cidade em 2001, tornaram-nas 
foco de diversos estudos e objeto de debate no campo do planejamento urbano no país.

Para aqueles que defendem 0 instrumento, a operação urbana é entendida como um mecanismo de recuperação da mais-valia da terra. A venda de potencial construtivo devolveria para a esfera pública a valorização dos imóveis fruto do próprio investimento público. Na mesma linha, a OUC é apontada como a única saída para a viabilização de grandes obras e intervenções urbanas em tempos de crise fiscal do Estado, pois consistiria em um instrumento autofinanciável.

No entanto, estudos como o de Fix (2004), a exemplo da experiência paulista, apontam para diversos problemas por trás desta suposta "fórmula mágica" por meio da qual cidade e mercado sairiam ganhando. A saber, Fix destaca que o pressuposto indispensável do interesse do mercado imobiliário de aderir às OUCs faz com que estas tendam a se concentrar em locais já privilegiados da cidade: regiões onde as novas obras urbanas atuarão para reforçar a concentração de renda, produzindo e legitimando a segregação socioespacial. Para a autora, mesmo que a operação seja bem-sucedida financeiramente, o risco e o investimento inicial, tanto operacionais como orçamentários - incluindo grandes obras iniciais para atração do mercado, chamadas de "âncora" -, são públicos e tomados em detrimento de outras ações. Dessa forma: "as restrições orçamentárias não são superadas, como se diz, mas apenas dribladas" (FIX, 2004, p. 3). Ou seja, as operações urbanas, ao contrario de constituírem-se como ferramentas para a recuperação da mais-valia da terra, funcionariam como "mecanismo[s] para que apenas uma fração da cidade continue a resolver seus problemas, utilizando o Estado como instrumento privado de acumulação" (FIX, 2004, p. 11).

Essas críticas são rebatidas no campo teórico por Monteiro (2014), a partir de uma defesa da neutralidade do instrumento. Segundo a autora, o instrumento OUC conservaria o potencial de funcionar como um complexo sistema de viabilização de políticas públicas, uma vez contornados os impactos negativos observados em experiências prévias. Nas palavras de Monteiro (2014, p. 27), a redenção deste instrumento até então mal utilizado seria possível por meio do "reconhecimento de especificidades locais, [da] repartição de ônus e de benefícios inerentes aos processos de urbanização e [da] participação dos atores citadinos na decisão sobre intervenções socioterritoriais".

O argumento da neutralidade do instrumento, que permite um explícito paralelo à reinvindicação da neutralidade da própria técnica em seu caráter científico, é precisamente a base em que se apoiam os técnicos envolvidos no processo de implementação da OUC Antônio Carlos/Pedro I + Leste-Oeste pela Prefeitura de Belo Horizonte. Assim, a polêmica em torno das disfunções/ 
potencialidades intrínsecas às OUCs como instrumentos técnicos, somada ao fato de a "participação dos atores citadinos" aparecer no discurso técnico e teórico como componente para a redenção do instrumento conferem grande relevância para a escolha do objeto deste estudo.

\section{Histórico da proposta: predefinição projetual}

O plano urbanístico da OUC ACLO em sua versão mais recente afeta diretamente cerca de $10 \%$ do território do município de Belo Horizonte, compreendendo o entorno de dois importantes eixos viários partindo da região central no sentido norte e conectando os limites municipais de leste e oeste. Trata-se de um projeto absolutamente significativo em termos territoriais fruto de um polêmico e conturbado histórico. As duas figuras apresentadas a seguir (Figuras 1 e 2), uma linha do tempo e um conjunto de mapas, ilustram as transformações conjunturais e territoriais deste projeto ao longo do tempo que serão discutidas na sequência.

Desde a revisão do Plano Diretor Municipal, em 2010, a Secretaria Adjunta de Planejamento Urbano (Smapu) da Prefeitura de Belo Horizonte $(\mathrm{PBH})$ desenvolvia internamente a proposta de uma OUC para o entorno dos corredores viários das Avenidas Antônio Carlos e Dom Pedro I, área coincidente com o eixo norte da atual OUC ACLO. Paralelamente, a partir de 2012, um consórcio de empresas do setor imobiliário, por meio de um Processo de Manifestação de Interesse (PMI), passa a desenvolver o projeto de uma segunda OUC compreendendo o vale do Ribeirão

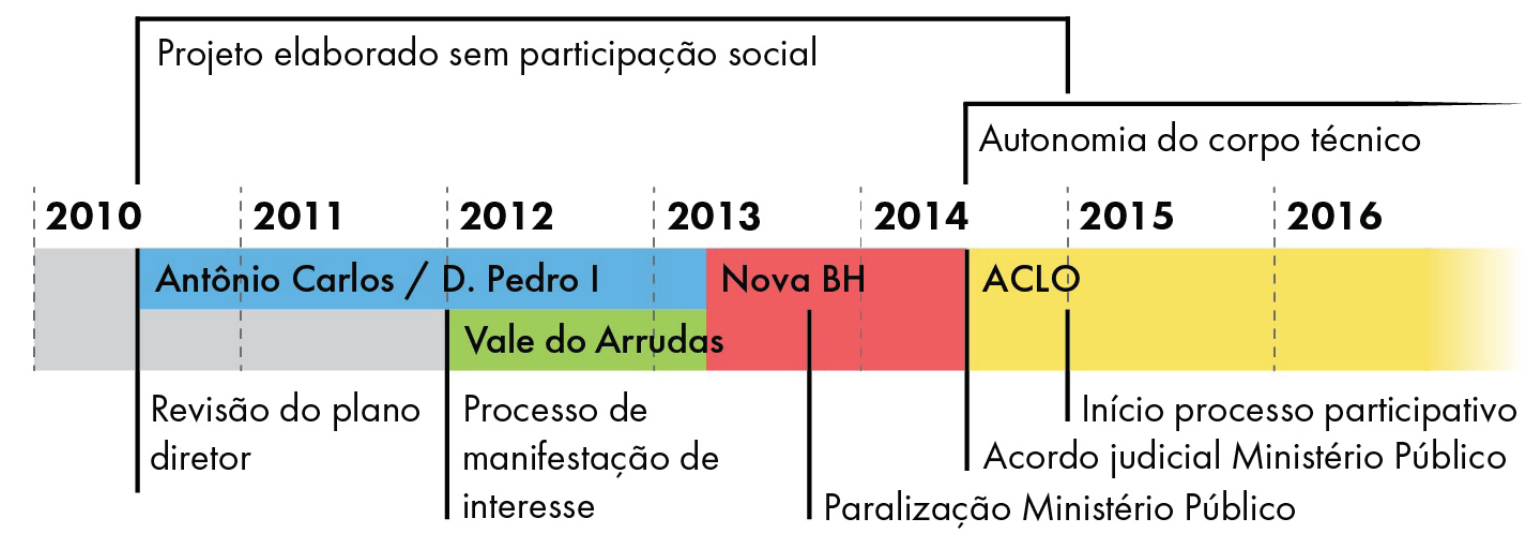

Figura 1. Histórico de elaboração da proposta da Operação Urbana Consorciada Antônio Carlos/Pedro I + Leste-Oeste (OUC ACLO). Fonte: Acervo da Autora. Dados aproximados, a partir de eventos noticiados e/ou discutidos em entrevistas 
Arrudas, área coincidente com o eixo leste/oeste da atual OUC ACLO. Em meados de 2013, esses dois projetos são unificados sob o nome de "OUC Nova BH". No mesmo ano, o projeto chega a ser aprovado pelo Conselho Municipal de Política Urbana (Compur) - importante etapa na efetivação de políticas e planos urbanísticos no município -, antes de ser paralisado pelo Ministério Público (MP) que investigava irregularidades em sua condução. Entre as irregularidades investigadas pelo MP, destaca-se a ausência de um processo de participação social. Assim, os termos do acordo judicial firmado entre a PBH e o MP que permitiu que a Smapu, sob a coordenação de um novo secretário, retomasse os estudos da Operação - então rebatizada de OUC ACLO - condicionavam justamente o cumprimento de protocolos predefinidos para a participação.

A mais evidente constatação possível a partir desse histórico é o avançado estágio de desenvolvimento em que o projeto se encontrava quando iniciado o processo participativo. Por sua vez, o adiantamento do projeto implica em limitações
Corredor viário Av. Antônio Carlos e Av. Dom Pedro I

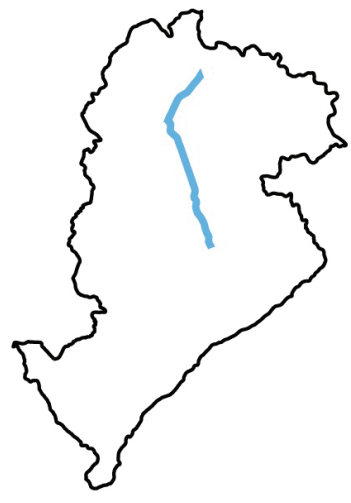

estudado para implementação de OUC pela PBH
Corredor viário vale do Ribeirão Arrudas

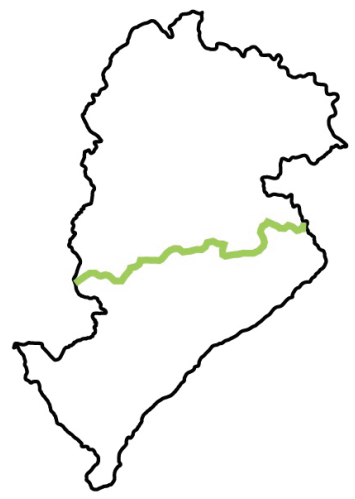

estudado para implementação de OUC por consórcio privado
Proposta OUC Nova BH

Proposta OUC ACLO
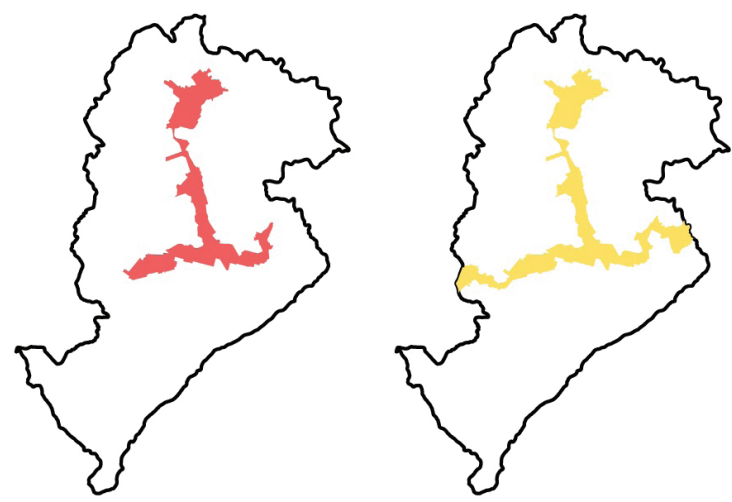

Figura 2. Tranformações territoriais da proposta de uma Operação Urbana Consorciada para o entrono de dois eixos viários (centro - norte / leste - oeste) no município de Belo Horizonte. Fontes: Dados coletados a partir do Caderno de Mapas que compõe o Plano Urbanístico e o Estudo de Impacto de Visinhança da Operação Urbana Consorciada Antônio Carlos/Pedro

I + Leste-Oeste (OUC ACLO); extraídos de http://oucbh.indisciplinar.com/?page_id=17; e aproximados, a partir de questões noticiadas e/ou discutidos em entrevistas. 
a respeito do que estaria de fato aberto para discussão e para tomada de decisão coletiva, uma limitação que os técnicos da Smapu reconhecem, tal como em registrado em entrevista:

Na verdade, essa proposta que a gente apresentou depois ela já existia aqui dentro. (...) A gente achava que nem era ético a gente falar assim: "Vamos fazer um diagnóstico." (...) Existe um projeto, ele é muito claro, não está nesse momento mais da gente fazer um diagnóstico. (...) Então assim, a primeira premissa nossa era isso: "Já existe uma proposta." Então o que a gente vai trabalhar ao máximo é que ela seja aberta, pra que a gente consiga incorporar, mas dentro das possibilidades que ela tem de abertura porque ela [a proposta] tem uma coisa muito estrutural já e tal. (...) então o que a gente teve de contribuição... Não tiveram contribuições estruturais na proposta.

O processo participativo da OUC ACLO envolveu 7 distintos formatos institucionais em um total de 42 eventos, elaborados e coordenados pelo corpo técnico da Smapu. Um total de 17 desses eventos foram acompanhados para a realização deste trabalho. Os discursos problematizados a seguir foram selecionados a partir desse acompanhamento acrescido de um total de 27 entrevistas realizadas com agentes envolvidos no processo, incluindo participantes e técnicos. Tratam-se de depoimentos que se destacaram tanto em relação à sua representatividade semeIhante à argumentações de outros agentes como no tocante à clareza de sua expressão pertinente à argumentação aqui proposta.

\section{Técnico versus participativo}

\section{Interpretações de uma perspectiva técnica}

Reconhecida a impossibilidade da neutralidade ou da autonomia da ciência, apesar de sua reivindicação do contrário, entende-se que para além dos métodos de geração de conhecimento que a caracterizam, a técnica inexoravelmente carrega as perspectivas político-ideológicas dos agentes que a praticam (DEWEY, 2008). Ou seja, torna-se evidente que a perspectiva técnica dos responsáveis pela condução dos processos participativos aqui analisados, se encontrava embebida das concepções político-ideológicas desses indivíduos.

Buscando melhor compreender como esses posicionamentos por parte dos especialistas eram interpretados pelos cidadãos no decorrer do processo participativo vinculado à OUC ACLO propõe-se, inicialmente, um melhor entendimento a respeito do entendimento dos próprios técnicos a respeito do processo de planejamento por eles conduzido. Nesse sentido, destaca-se a conjuntura político-institucional no âmbito da Secretaria Adjunta de Planejamento Urbano durante o período em que é elaborado o projeto da OUC ACLO, descrita por uma das técnicas responsáveis pelo projeto da seguinte forma:

[após a paralização da OUC Nova BH] o cenário político macro mudou (...), o secretário mudou e eu acho que a mudança do secretário foi essencial pro processo. Nem tanto pelas propostas dele, porque ele deixou meio livre, (...), então foi 
uma coisa que acabou muito conduzida pelos técnicos, com o aval dele. Ele confiou nos técnicos, ele já conhecia a equipe. "Super confiável", primeira coisa que ele falou: "Confio na equipe, então vamos lá." (...) acho que o prefeito também, com toda a pressão, com todas as coisas, ele meio que abandonou naquele momento o barco. Ele deixou correr, não sabia. A gente tinha pouquíssimas reuniões com o Governo (...) E depois ele [o secretário] comprou perante o prefeito, que foi super importante. ${ }^{2}$

A partir da fala supracitada, destaca-se que os próprios técnicos da Smapu afirmavam gozar de grande autonomia frente à Secretaria de Governo em relação à elaboração do projeto da OUC ACLO, configurando um cenário em que o exercício de sua perspectiva técnica de forma independente se encontrava favorável. Destaca-se também, a partir da fala dessa mesma técnica, o particular envolvimento do corpo técnico da Smapu com o Plano da OUC ACLO, expresso em um singular apreço pelo projeto:

Então acho que a gente estava lá muito sincero, era um trabalho que a gente acreditava, então a gente tinha conforto de falar. $\mathrm{E}$ acho que também porque era um trabalho bom mesmo, eu acho, dentro dos limites do instrumento, dentro dos limites da experiência que a gente tem, porque é isso que a gente está falando, a gente está arriscando também. Tem muita coisa ali que a gente não testou. Mas eu acho que é mais porque o trabalho é bom. Vamos falar diferente: porque a gente acredita que o trabalho é bom, então a gente estava com uma clareza de defesa. ${ }^{3}$
Entende-se que a constituição de uma determinação como científica/técnica só é possível em conexão com os métodos pelos quais é alcançada (DEWEY, 2008). Assim, o "acreditar" e a "clareza de defesa" de seu próprio trabalho, ainda que esse apresentasse "riscos" e dimensões "não testadas", reforçam o entendimento de que posicionamentos político-ideológicos desses técnicos se encontravam representados no projeto da OUC ACLO. É nesse contexto que se destacam as interpretações de dois participantes, notáveis a partir dos depoimentos apresentados a seguir:

Então o que está havendo entre o urbanista e o político? Nós, atualmente, estamos tentando mudar um pouco a conotação desse país, nesse sentido de só o político mandar, só o político resolver, só o político determinar. O poder público tem que participar, mas ele não pode participar urbanisticamente. Ele não pode dar palpite. (...) Então existe aqui um confronto entre a situação urbana e a situação política. (...) Então eu acho, primeiro, que o pessoal da OUC ACLO é um pessoal criado pelos políticos, está dentro da Prefeitura. Trabalham para a Prefeitura, fazem o que a Prefeitura está querendo fazer. (...) E vai tentar resolver isso, antes de entregar a Prefeitura, porque vai ter agora eleição. Então vão mudar os vereadores, vai mudar o prefeito e tal, e eles querem ser os donos dessa nova Operação, OUC ACLO ou qualquer coisa assim, eles querem votos. E urbanista não quer votos. (...) Então, quem manda primeiro? O urbanista. Depois pode vir os políticos, os empreiteiros, o povo, pode vir todo mundo falar. (...) A conclusão do meu negócio é o seguinte: urbanista tem que 
mandar e urbanista não está mandando. Urbanista está urbanizando a mando do político. ${ }^{4}$

Agora com relação a essa participação eu acho que ela é importantíssima, mas eu acho que ela tem que ser dosada, por que? Não necessariamente o que a gente quer ou gostaria é o meIhor pra cidade ou melhor pra região, por que? Porque nós não temos conhecimento técnico necessário. Mas eu acho que essa discussão ela tem que realmente ser selada, terminada com essa parte técnica, que aí vê a coisa como um todo, de uma maneira profissional e não amadora. Porque muitas vezes a gente: "Queria isso." Mas é péssimo, é inviável. Eu acho que tem que ser ouvida a população, mas ela não pode ditar também de que maneira ou se é viável, enfim, então minha opinião é essa. (...) A população tem que falar uma coisa, mas se o técnico que está lá. Um técnico não cooptado seja pelo poder público, seja pelo poder empresarial, a população lá também vai aceitar os argumentos, e o que a gente viu lá não foi [isso]. ${ }^{5}$

Ambos os participantes supracitados, ao longo de suas entrevistas, demonstravam estar em desacordo com as determinações alcançadas pelo Plano Urbanístico da OUC ACLO - então em vias de finalização. Buscando não entrar no mérito dos interesses que os levavam à sua insatisfação, é evidente em suas falas o questionamento do caráter técnico do processo que conduz a essas decisões com o objetivo desqualificá-las. O primeiro participante enquadra as determinações sustentadas pelos técnicos da Smapu como frutos de interesses "políticos" vinculados à gestão municipal vigente, em oposição a um ideal positivista da téc- nica urbanística. De forma semelhante, a segunda participante desqualifica as decisões compiladas no Plano Urbanístico acusando o processo participativo do desvirtuamento de sua tecnicidade.

Em princípio, tais declarações poderiam ser entendidas simplesmente como o reflexo de um desconhecimento por parte desses participantes da conjuntura de forças em atuação sobre o processo de elaboração da OUC ACLO - e talvez o sejam. No entanto, a confiança depositada na inteligência e inventividade dos agentes envolvidos nos processos participativos analisados e a atenção extrema à sua mobilidade tática - postura inspirada a partir da teoria de Certeau - lança outra luz sob esses discursos. Em suma, permite entender tais interpretações como formas encontradas por esses participantes de integrarem-se à disputa pela construção da realidade a partir da manipulação, alteração e inversão de um discurso de poder: o discurso da técnica como científica, neutra e autônoma.

O que se destaca a respeito da interpretação que fazem esses dois participantes a respeito das decisões expressas no Plano Urbanístico da OUC ACLO e, consequentemente, da perspectiva político-ideológica dos técnicos por elas responsáveis é o reconhecimento de seu caráter "não técnico" ou não neutro. No entanto, contraditoriamente, em negação a perspectiva dos técnicos responsáveis pelo projeto, esses participantes reafirmam a força do técnico por meio do consumo de sua materia- 
lidade simbólica. Ao afirmar que de alguma maneira as decisões expressas no Plano Urbanístico da OUC ACLO haviam sido impostas aos técnicos - seja por pressões políticas externas ou pelo processo de participação social, ambos se infiltram em um espaço construído, escrito e pré-fabricado de verdade - de uma ciência pragmaticamente neutra e autônoma - manipulando-o, alterando-o e invertendo-o discretamente em defesa de interesses e desejos particulares.

Especialmente nesse contexto, destaca-se a possível influência da formação das entrevistadoras como arquitetas/urbanistas junto ao processo comunicacional que gerou tais depoimentos. Uma vez que a presença de especialistas pode ter influenciado a decisão por parte desses participantes de consumo de um discurso que preza pela cientificidade do urbanismo, como forma de atuar sobre o querer de suas interlocutoras.

\section{Questionamento e exaltação de um processo participativo}

Para além do consumo da materialidade simbólica do discurso técnico, julgou-se significativa a observação de apropriações semelhantes do discurso democrático realizadas por uma participante do processo vinculado à OUC ACLO e um dos técnicos responsáveis pelo projeto. A seguir, são destacados trechos da entrevista em que a mencionada participante - que, como aqueles citados anteriormente, encontrava-se insatisfeita com as determinações do Plano Urbanístico - descreve um episódio ocorrido durante uma das oficinas participativas promovidas pela Smapu:

Aí ele [um participante] pega e escreve: "Possibilidade de retirada dos estacionamentos da Avenida [nome suprimido], garantindo a manutenção da área de carga e descarga". Ele escreveu isso, esse rapaz escreveu isso. Eu estava até branca de tanto falar que não, que não, de tanto lutar. (...) Que espécie de consulta à comunidade é essa? (...) Olha o que eu coloquei aqui, (...): "Os lojistas do associação [nome suprimido] não querem redução das vagas de estacionamento na Avenida." Não querem. Aí ele pega e faz um trem desse. Quem que a Prefeitura escuta? Quem que o projeto vai atender? Aí falaram comigo assim: "Achei que você estava negociando com ele." Falei: "Uai, eu negociando com ele como?", "Não, porque esse cara não pertence a Prefeitura." E eu falei assim: "Então ele pertence a quem? Porque ele não pertence à comunidade". (...) Agora, se deram ouvidos pra ele e ele é um ninguém, (...) eu me sinto menos que ninguém, porque se o ninguém escreveu e foi acatado, e a representante da associação [nome suprimido] e a comunidade toda do bairro [nome suprimido] não foi ouvida. (...) Eu achei um absurdo. (...) Porque eu não fui ouvida. Eu participei, me tiraram do sério ali, eu cheguei até a dar um tapa na mesa lá, eu falei: "Não vai ter, na Avenida [nome suprimido] vocês não vão fazer isso." Gente, pelo amor de Deus, (...) como que podem fazer um projeto sem chamar na mesa? (...) De maneira geral, o que eu posso te dizer é que eu não fui participada de nada. Nem eu, nem ninguém que eu conheço da minha roda de amizades foi participado de nada, então não existe participação. ${ }^{6}$
Setor empresarial - associação comercial. Fala registrada em entrevista em 6/10/2015. 
Novamente, buscando não entrar no mérito dos interesses que levavam essa participante à insatisfação com as determinações do Plano Urbanístico da OUC ACLO, é evidente em sua fala o questionamento do caráter participativo dessas determinações como tentativa de desqualificá-las. De forma não muito distinta daqueles participantes que questionavam o caráter técnico de tais decisões, essa participante, ao consumir a materialidade simbólica de um discurso democrático, apropria-se de um espaço de verdade - a obrigatoriedade da gestão democrática por meio da participação social determinada pelo Estatuto da Cidade -, onde se infiltra em defesa de interesses e desejos particulares. Apesar de haver comparecido a um evento participativo e pleiteado uma proposta específica entre os demais participantes e organizadores do evento, ao ver sua perspectiva desfavorecida, ela nega veementemente a existência de qualquer participação.

Nesse sentido, o discurso dessa participante permite reconhecer nas práticas participativas institucionalizadas, por mais enrijecidas e criticáveis que sejam, assim como no Estatuto da Cidade e nos marcos legais que o precederam ou dele derivaram, a confirmação de uma concepção defendida por Holston (2013). O autor argumenta que a legislação, a burocracia e as práticas a elas associadas têm um papel fundamental na construção de uma consciência democrática no contexto brasileiro, pois, ao incutir uma noção de direitos e deveres, poderes e responsabilidades, estatutos e procedimentos, ela permite a exploração de suas sutilezas e complicações como táticas ou contra estratégias de ação social.

Holston (2013) também aponta para o fato de que a construção dessa consciência democrática é caracteristicamente lenta e parece desapontar primeiro, idiossincraticamente, entre aqueles que já acumulavam capitais, simbólicos ou não. Esse tipo de antecipação pelo mais forte da oportunidade de apropriação de uma noção de direito pode ser evidenciado a partir do discurso de um dos técnicos da Smapu que, de forma semelhante à participante supracitada, durante um evento realizado em um dos bairros afetados pela OUC ACLO, por sua vez, recorre à reafirmação da legitimidade do processo participativo vinculado ao projeto como forma de defendê-lo:

A gente tem visto que quanto mais a gente conversa melhor fica, maior a qualidade do nosso produto, da nossa proposta, tá? E a gente tem de fato apostado nisso. Essa proposta da operação, o projeto foi realmente construído de forma coletiva, tá? A gente fez, muitas vezes a gente fez um processo de discussão pública, então, "vou consultar pra constar que eu consultei", "vou fazer uma média pra constar". Não. A gente recebeu de fato mais de 800 propostas, se vocês forem ver no plano urbanístico. A gente tem a lista de todas as propostas, de quando ela foi colocada, por quem e quais foram incluídas ou não no projeto. A maioria foi incluída sim, tá? Inclusive algumas propostas estruturantes. ${ }^{7}$
Coordenação OUC ACLO.

Fala registrada em apresen-

tação do projeto realizada em 30/09/2015. 
A defesa pública do caráter de "construção coletiva" do Plano Urbanístico da OUC ACLO realizada por esse técnico da Smapu contradiz o discurso franco por parte de sua equipe registrado em entrevista a respeito da predefinição estrutural do projeto, destacado anteriormente. Em defesa de sua perspectiva, convicções e desejos que, como já destacado, pareciam se encontrar respaldados pelas decisões compiladas junto ao Plano da OUC ACLO, ele se apropria estrategicamente (inclusive da disponibilização numericamente exaustiva de "propostas" e "respostas" exigida pelo Ministério Público como parte do acordo judicial que permite a retomada do desenvolvimento do projeto da OUC) como evidência da legitimidade de uma construção coletiva do projeto.

\section{Finalizando}

Extrapolando o processo participativo aqui estudado como encenação de uma disputa que o transcende, destaca-se que a apropriação do discurso da participação, ao lado do discurso técnico, assim como a paralisação do projeto da Nova $\mathrm{BH}$, vinculada a um déficit de participação social, como indícios de que o discurso técnico sozinho não tem se bastado como discurso de verdade no contexto da produção do espaço urbano. A disputa pela cidade parece ter se acirrado em torno da capacidade de apropriação de informações e con- junturas para a defesa de interesses, convicções e desejos por meio do consumo da materialidade simbólica desses dois discursos. Aqueles cujas perspectivas foram acatadas defendem a tecnicidade, a neutralidade, a autonomia e o caráter democrático das decisões alcançadas, enquanto aqueles cujas perspectivas não foram atendidas clamam por "mais técnica" que defenda meu ponto de vista e "mais participação" de mim mesmo.

São indícios não apenas da difusão do reconhecimento do direito à cidade como uma fonte objetiva de direito na luta por uma vida cotidiana merecedora da dignidade, explicitado na noção de poder subjetivo que leva ao acionamento do discurso democrático como estratégia de disputa pela tomada de decisão no caso analisado. Mas também, indícios de que a disputa em torno do significado desses termos - acerca do que é entendido como participação, assim como acerca do que é entendido como técnico - tem se constituído como uma poderosa via de critica à legitimidade de processos de tomada de decisão vinculados ao planejamento urbano e à produção da cidade como um todo. Torna-se evidente a relevância dessa disputa simbólica para a construção discursiva e contextual de relações de cidadania a partir da arena estratégica da cidade e assim como para uma produção mais democrática do espaço. 


\section{Referências:}

ARTURO, Escobar. Planning. In: SACHS, Wolfgang. The Development Dictionary: a guide to knowledge as power. London \& New York: Zed Books, 2010.

AZEVEDO, Heloísa Pereira Lima. Planejamento e Gestão Municipal: planos diretores - avanços e alertas na implementação. In: FARIA, Rodrigo de; SCHVARSBERG, Benny. (orgs.). Políticas urbanas e regionais no Brasil. Brasília: Universidade de Brasília, Faculdade de Arquitetura e Urbanismo, 2011.

BOURDIEU, Pierre. Language and symbolic power. Cambridge: Polity Press, 1992.

BRASIL. Estatuto da Cidade - Lei no 10.257, de 10 de julho de 2001. Regulamenta os arts. 182 e 183 da Constituição Federal, estabelece diretrizes gerais da política urbana e dá outras providências. Diário Oficial [da] República Federativa do Brasil, Brasília, DF, 10 jul. 2001.

CERTEAU, Michel de. A invenção do cotidiano: artes de fazer. Petrópolis: Vozes, 1994.

DEWEY, John. Democracia cooperativa: escritos políticos escolhidos de John Dewey (19271939). Conferência Mundial sobre o Desenvolvimento de Cidades Tradução: Traduzca, 2008.
FIX, Mariana. A "fórmula mágica" da parceria público-privada: Operações Urbanas em São Paulo. Urbanismo: dossiê São Paulo-Rio de Janeiro. Campinas: PUCCAMP/PROURB, p. 185-198, 2004.

HOLSTON, James. Cidadania insurgente: disjunções da democracia e da modernidade no Brasil. Tradução Claudio Carina; revisão técnica Luísa Valentini. São Paulo: Companhia das Letras, 2013.

LEFEBVRE, Henri. $\mathbf{O}$ direito à cidade. Tradução Rubens Eduardo Frias. São Paulo: Centauro, 2001. Título original: Le Droit à la Ville.

MARICATO, Ermínia; SANTOS JUNIOR, Orlando Alves dos Santos. Construindo a Política Urbana: participação democrática e o direito à cidade. Teoria e Debate. São Paulo, n. 66, abr-jun 2006.

MARICATO, Ermínia. Erradicar o analfabetismo urbanístico. Revista FASE. Março de 2002.

MONTE-MÓR, Roberto Luís. O que é o urbano no mundo contemporâneo. Belo Horizonte: UFMG/Cedeplar, 2006.

MONTEIRO, Lívia de Oliveira. Espacialidades e especificidades: as operações urbanas consorciadas como ferramenta de planejamento 
e de gestão do espaço. Tese (Doutorado em Arquitetura e Urbanismo) - Núcleo de Pós-graduação em Arquitetura e Urbanismo, Escola de Arquitetura e Urbanismo, Universidade Federal de Minas Gerais (EA-UFMG), 2014.

MONTENEGRO, Antônia Maria da Rocha. Planejamento, participação social e reformas administrativas: a experiência da Prefeitura de Belo Horizonte nos 16 anos de governo democrático popular. Tese (Doutorado em Arquitetura e Urbanismo) - Programa de Pós-graduação em
Ciências Sociais da Pontifícia Universidade Católica de Minas Gerais PUC-MG, 2011.

RAHNEMA, Majid. Participation. In: SACHS, Wolfgang. The Development Dictionary: a guide to knowledge as power. Second edition. London \& New York: Zed Books, 2010.

RIBEIRO, Luíz Cesar de Queiroz; CARDOSO, Adauto Lucio. Planejamento urbano no Brasil: paradigmas e experiências. XIV Encontro Anual da Associação Nacional de Pós-Graduação em Ciências Sociais. Caxambu: ANPOCS, 1990. 